\title{
Modelling Reaeration Phenomenon In River Using Dimensionless Approach
}

\author{
[Anuradha Pandey1 and Ram Pal Singh2*]
}

\begin{abstract}
This communication presents a methodology to evaluate the re-aeration rate term in basic dissolved oxygen (DO) deficit models by including some important parameters influencing re-aeration phenomenon in river like turbulence, width, depth and length of streams, which are necessary for fast biochemical oxygen demand (BOD) assimilation in streams. A mathematical model using dimensional approach for rate of re-aeration as well as DO deficits, using basic philosophy of Bhargava (1986) model, is presented. The simulation of data on river Ganges in India, indicate that the predictions of DO deficits are in close agreement with the experimentally observed values. The methodology presented in this paper accounts for all the important factors affecting reaeration in streams and thus, may offer an alternative to traditionally used approaches for representing re-aeration rate in rivers/streams.
\end{abstract}

Keywords- Dissolved oxygen; $B O D$ assimilation; DO deficit; Critical time; Re-aeration coefficient; River Ganges.

\section{Introduction}

Dissolved oxygen (DO) in river is one of the most important indices for assessing the river's health and is a prime consideration in streams assimilation capacity. Many factors affect the DO concentration in river water and can be broadly classified into three main categories, namely 1) Geophysical factors, 2) Bio-chemical factors and 3) Physical factors. Geo-physical factors include river flow, temperature of water body, climatic conditions, surface expanse, turbulence, type and amount of organic matter and the depth of the water body. Bio-chemical \& physical forces include dilution and dispersion, mass-transfer phenomena, photosynthetic activities, bio-oxidation and reduction processes and all the natural and man-made sources and sinks of dissolved oxygen. Polluted streams are usually characterized by a decline in DO level followed by a recovery in the DO level along the length of stream. The initial decrease in DO level occurs due to greater rate of oxygen removal by biological oxidation than that recouped by re-aeration. The rate of biological oxidation is directly proportional to the quantity of organic material present and consequently decreases with time. The minimum DO deficit will occur at a point where the rate of supply of oxygen by re-aeration equals the rate of its consumption by biological oxidation. Thereafter, the re-aeration process dominates and the dissolved oxygen deficit is gradually reduced.

Anuradha Pandey

Motilal Nehru National Institute of Technology (MNNIT) Allahabad India-211004

Professor Ram Pal Singh

Motilal Nehru National Institute of Technology (MNNIT) Allahabad India-211004
A number of mathematical models for DO deficit [Streeter and Phelps (1925), Fair (1939), Bhatia and Mc. Bean (1986) and Bhargava (1986)] have been developed to assess the DO behaviour in streams. Little or no attention has been paid towards the modification of re-aeration rate term, which depends upon the number of variables. Also, the river Ganges in India is famous for fast biochemical oxygen demand (BOD) assimilation capacity (Bhargava 1983). Therefore, there is a need to incorporate the important variables affecting the re-aeration phenomenon so that the condition of river can be described in a better way.

In the present paper, the original DO deficit model developed by Bhargava (1986), which was originally derived from Streeter and Phelps (1925) DO model, has been modified by replacing the re-aeration rate term by a new term. In Bhargava (1986) model, the BOD assimilation term was divided into two fractions, i.e. settleable and nonsettleable fractions. But, no attention was paid by earlier investigators to modify/replace the rate of re-aeration term $\left(r_{R}\right)$, which is of great significance in faster self-purification of streams. From the literature, it is evident that the term ' $r_{R}$ ' is largely influenced by the river's characteristics such as width, depth, turbulence, velocity of flow, length along the course of river, time of travel as well as the initial and saturation DO levels of stream. Keeping these factors in view, a dimensional analysis is performed to derive a dimensionless expression for the re-aeration rate term and the same was incorporated in Bhargava (1986) model for further prediction of DO deficits in streams. The reported data from the study of Bhargava (1986) on river Ganges in India has been used for predictions and the results were also compared with the observed values. It is believed that the methodology presented in this paper will prove better to represent comprehensively the re-aeration rate rather than representing ' $\mathrm{r}_{\mathrm{R}}$ ' by a single parameter, the re-aeration coefficient, ' $k_{R}$ ', as used by many previous researchers.

\section{Theoretical Background}

When an organic effluent is discharged into a stream, it exerts BOD with the processes of BOD assimilation and atmospheric re-aeration proceeding simultaneously. In many situations the oxygen demand will initially exceed the reaeration rate, so the DO concentration will fall rapidly. If the rate of consumption lowers the oxygen concentration, the oxygen mass transfer rate will increase. At some point downstream of point of discharge the rate of re-aeration and the rate of consumption becomes equal and the oxygen concentration stops declining. This is the critical point of the curve, where the oxygen deficit is maximum and the dissolved oxygen concentration is lowest, called as critical DO deficit $\left(D_{c}\right)$ and the corresponding time is called as critical time $\left(\mathrm{t}_{\mathrm{c}}\right)$. Thereafter, re-aeration phenomenon predominates and the dissolved oxygen concentration rises to approach saturation DO level. As the rate of mass transfer 
is proportional to the oxygen concentration, the rate of reaeration slows down near the asymptotic point.

As per Streeter and Phelps (1925), the rate of DO deficit (D) can be expressed as a function of BOD assimilation and re-aeration rates, which is the algebraic sum of rate of deoxygenation $\left(\mathrm{r}_{\mathrm{D}}\right)$ and the rate of re-aeration $\left(\mathrm{r}_{\mathrm{R}}\right)$ and is given by the expression:

$$
\frac{d D}{d t}=r_{D}+r_{R}
$$

where, $\frac{d D}{d t}=$ the rate of change of DO deficit.

Both $r_{D}$ and $r_{R}$ follow first order kinetics with respect to $\mathrm{BOD}$ of waste and $\mathrm{DO}$ deficit ' $\mathrm{D}$ ' respectively and are expressed as:

$$
\begin{aligned}
& r_{D}=\frac{d D}{d t}=k S \\
& r_{R}=-k_{R} D
\end{aligned}
$$

where, $\mathrm{k}=$ de-oxygenation rate constant $\left(\mathrm{d}^{-1}\right)$, and $S=$ BOD remained after time $t, \mathrm{mg} / \mathrm{L}$. Therefore, Eq. (1) becomes

$$
\frac{d D}{d t}=k S-k_{R} D
$$

As per Bhargava (1986), the DO Deficit in the river due to discharge of wastewater is affected by the settling of settleable organic particles. If the settleable portion of the initial BOD concentration is $S_{0-x}$, which would be completely removed within a transition time ' $T=\frac{d}{v}$ (days)' where $d=$ depth of river, $\mathrm{m}, v=$ settling velocity of bio-flocculated particles $(\mathrm{m} / \mathrm{s})$. If $S_{0-y}$ is the non-settleable organic fraction $(\mathrm{mg} / \mathrm{l})$, then, the total initial BOD, ' $S_{0}$ ' will be given by

$$
S_{0}=S_{0-x}+S_{0-y}
$$

The settled fraction of settleable portion of initial BOD concentration $\left(S_{o-x}\right)$, at time ' $t$ ' is given by $S_{o-x} \frac{v}{d} t$.

Therefore, the non-settleable fraction $\left(\mathrm{S}_{1}\right)$ of settleable portion of initial BOD concentration $\left(S_{o-x}\right)$, at time ' $t$ ', is given by

$$
S_{1}=S_{o-x}-S_{0-x} \frac{v}{d} t
$$

The non-settleable portion $\left(S_{2}\right)$ of total initial BOD concentration $\left(S_{0}\right)$, at time $t$ is given by,

$$
S_{2}=S_{0-y} e^{-k t}
$$

Where, $\mathrm{k}=\mathrm{BOD}$ rate constant for settleable organic matter.

Hence, BOD remaining at time ' $t$ ' will be expressed as:

$$
S=S_{1}+S_{2}=S_{0-x}\left(1-\frac{v}{d} t\right)+S_{0-y} e^{-k t}
$$

Bhargava (1986) has mentioned that non-settleable organic matter exerts the oxygen demand at a maximum rate equal to the rate of BOD exertion $(k)$. But, the settleable organic matter would exert a part of its oxygen demand before it reaches the bottom of the streams and this rate constant is denoted as ' $m$ '. It is to be noted that this rate constant of oxygen demand $(m)$ may be even more than $k_{R}$, such that the maximum value of $m$ would equal to $k_{R}$. Thus, $k$ for the first term of the right hand side of the Eq. (8) should be ' $m$ ', and for the second term of right hand side of the Eq. (8) would be 'k'. From Eqs. (4) and (8), we have,

$$
\frac{d D}{d t}=m S_{0-x}\left(1-\frac{v}{d} t\right)+k S_{0-y} e^{-k t}-k_{R} D
$$

The exact solution of Eq. (9), for $t<T$ (Transition time), $\mathrm{t}=\mathrm{T}=\mathrm{d} / \mathrm{v}$ and $\mathrm{t}>\mathrm{T}$ can be expressed respectively by Eqs. (10), (11) and (12).

$$
\begin{aligned}
& D=\left(\frac{m}{k_{R}}\right) S_{0-x}\left\{1-e^{-k_{R} t}\left[1+\left(\frac{1}{k_{R}}\right)\left(\frac{v}{d}\right)\right]-\left(\frac{v}{d}\right)\left(t-\frac{1}{k_{R}}\right)\right\}+\left(\frac{k}{k_{R}-k}\right) S_{0-y}\left(e^{-k t}-e^{-k_{R} t}\right)+D_{0} e^{-k_{R} t} \\
& D_{T}=\left(\frac{m}{k_{R}}\right) S_{0-x}\left[\left\{1-e^{\left(-k_{R} \frac{d}{v}\right)}\right\}\left\{\left(1+\frac{1}{k_{R}}\left(\frac{v}{d}\right)\right)-1\right\}\right]+\left(\frac{k}{k_{R}-k}\right) S_{0-y}\left\{e^{\left(-k_{R} \frac{d}{v}\right)}-e^{\left(-k_{R} \frac{d}{v}\right)}\right\}+D_{0} e^{\left(-k_{R} \frac{d}{v}\right)} \\
& D=\frac{k}{k_{R}-k} S_{0-y}\left[e^{-k t}-e^{\left.\left\{\left(k_{R}-k\right) \frac{d}{v}-k_{R} t\right\}\right]}+D_{T} e^{\left\{-k_{R}\left(t-\frac{d}{v}\right)\right\}}\right.
\end{aligned}
$$

where $D_{T}$ is the DO deficit at $T=d / v, d=$ depth of river and $\mathrm{v}=$ settling velocity of bio-flocculated particles. Other model equations developed are reported elsewhere by (Bhargava 1986).

Bhargava (1986) did not propose any change in the reaeration rate term $\left(\mathrm{k}_{\mathrm{R}} \mathrm{D}\right)$. For fast river purification, this term has great significance and hence has been paid attention in this study. A dimensional approach is followed to modify the rate of re-aeration term as described below.

\section{A dimensionless approach for evaluation of rate of re- aeration and $\mathrm{DO}$ deficit}

It is well known that rate of re-aeration in streams depends upon a number of forces and factors. Among them, some relevant factors are DO deficit (D), re-aeration coefficient $\left(\mathrm{k}_{\mathrm{R}}\right)$, Reynolds number accounting turbulence $(R)$, initial DO of the river water $\left(C_{i}\right)$, saturation DO of the river water $\left(C_{s}\right)$, acceleration due to gravity $(g)$, length along course of river $(L)$, width of river $(B)$, depth of river $(d)$. Thus, the rate of re-aeration can be assumed as a function of all these parameters and can be expressed as:

$$
r_{R}=f\left(D, k_{R}, L, t, C_{i}, C_{s}, g, R, d, B\right)
$$

The repeating variables may be taken as $L, t, \mathrm{k}_{\mathrm{R}}$ and $C_{s}$.

Using Buckingham-Pi theorem, the various relevant dimensionless groups formed can be expressed as:

$$
\pi_{1}=\frac{r_{R} \cdot t}{C_{s}}=\frac{k_{R} \cdot D \cdot t}{C_{s}}
$$


Proc. of the Seventh International Conference On Advances in Civil and Structural Engineering - CSE 2017.

Copyright ( $)$ Institute of Research Engineers and Doctors. All rights reserved.

ISBN: 978-1-63248-127-6 doi: 10.15224/ 978-1-63248-127-6-37

Table 1: Observed and Predicted DO deficits

\begin{tabular}{ccccc}
\hline $\begin{array}{c}\text { Time, } \\
\text { days }\end{array}$ & $\begin{array}{c}\text { Distance from } \\
\text { point of } \\
\text { discharge }^{\mathrm{a}}, \mathrm{m}\end{array}$ & $\begin{array}{c}\text { Observed DO deficit } \\
\mathrm{b}, \mathrm{mg} / \mathrm{l}\end{array}$ & $\begin{array}{c}\text { Predicted DO deficit }^{\mathrm{c}}, \mathrm{D}, \\
\mathrm{mg} / \mathrm{l}\end{array}$ & $\begin{array}{c}\text { Predicted DO deficit }^{\mathrm{d}}, \\
\mathrm{D}, \mathrm{mg} / \mathrm{l}\end{array}$ \\
\hline 0.000 & 0.00 & 3.75 & 3.750 & 3.750000 \\
0.010 & 466.56 & 6.83 & 4.920 & 4.726915 \\
0.020 & 933.12 & 5.08 & 5.418 & 5.201299 \\
0.025 & 1166.40 & 4.80 & 5.445 & 5.228913 \\
0.050 & 2332.80 & 4.60 & 5.170 & 5.021416 \\
0.065 & 3032.64 & 4.15 & 5.000 & 4.892359 \\
0.075 & 3499.20 & 4.55 & 4.880 & 4.801045 \\
0.100 & 4665.60 & 4.35 & 4.590 & 4.549683 \\
0.110 & 5132.16 & 4.30 & 4.520 & 4.439106 \\
0.125 & 5832.00 & 4.95 & 4.210 & 4.262094 \\
0.150 & 6998.40 & 4.80 & 4.014 & 3.937328 \\
\hline
\end{tabular}

a.computed by multiplying time with velocity of flow.

b.extracted from study of Bhargava (1986)

c. as per Bhargava (1986) model

d. as per present model

$\pi_{2}=\frac{C_{i}}{C_{s}}$

$\pi_{3}=\frac{g t^{2}}{L}$

$\pi_{4}=\frac{B}{L}$

$\pi_{5}=R$

$\pi_{6}=\frac{d}{L}$

Using these dimensionless groups, the parameter, $\frac{k_{R} \cdot D \cdot t}{C_{s}}$ can be expressed as function of other remaining dimensionless groups as:

$$
\frac{k_{R} \cdot D \cdot t}{C_{s}}=f\left[\frac{C_{i}}{C_{s}}, \frac{g t^{2}}{L}, \frac{B}{L}, R, \frac{d}{L}\right]
$$

As the variation of rate of re-aeration can be approximated as a power function of variables, therefore, the right hand side of Eq. (20) can be assumed as power function of multiplier of all the dimensionless groups and the resulting equation can be written as:

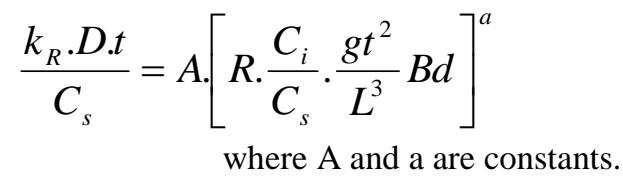

Eq. (21) can also be written equivalently in terms of velocity of flow $(\mathrm{V})$ in place of $\mathrm{L}$ and is given by

$$
\frac{k_{R} \cdot D \cdot t}{C_{s}}=A \cdot\left[R \cdot \frac{C_{i}}{C_{s}} \cdot \frac{g}{V^{3} \cdot t} B d\right]^{a}
$$

\section{Results and Discussion}

From Eq. (21) or (22), the rate of re-aeration, $r_{R}\left(=k_{R}\right.$.D) can be determined by power fitting of the experimental data on streams. In the present work, the parameters required for fitting of Eqs. (21) or (22) were extracted from the study of Bhargava (1986) on river Ganges in India. The parameters' values extracted are: $m=9.0 \mathrm{~d}^{-1}, k=3.5 \mathrm{~d}^{-1}, k_{R}=9.0 \mathrm{~d}^{-1}, S_{0 \text { - }}$ ${ }_{x}=16 \mathrm{mg} / \mathrm{l}, S_{0-y}=12 \mathrm{mg} / 1, D_{0}=3.75 \mathrm{mg} / \mathrm{l}, T=d / v=0.025 \mathrm{~d}^{-1}$, $\mathrm{V}=0.54 \mathrm{~m} / \mathrm{s}, \mathrm{C}_{\mathrm{s}}=7.75 \mathrm{mg} / \mathrm{l}, \mathrm{C}_{\mathrm{i}}=4 \mathrm{mg} / \mathrm{l}, \mathrm{B}=120 \mathrm{~m}$, and $\mathrm{d}$ $=5 \mathrm{~m}$. The Reynold's number ' $\mathrm{R}$ ' was determined using the relation:

$$
R=\frac{V B d}{v \cdot(B+2 d)}
$$

where $v=$ kinematic viscosity of water $=101 \times 10^{-6} \mathrm{~m}^{2} / \mathrm{s}$.

Using Eq. (23) and parameters values, the Reynold's Number, R was computed as 2467631. The functional relationship between the parameters of Eq. (21) was derived by power fitting of the data presented in Table 1 using observed DO deficit, D (read from Fig. 1 of the study of Bhargava (1986)) and the time, $t$ as shown in Figure 1. The following functional relationship was obtained with $\mathrm{R}^{2}-$ value of 0.9851 .

$$
\frac{k_{R} \cdot D \cdot t}{C_{s}}=506005 \cdot\left[R \cdot \frac{C_{i}}{C_{s}} \cdot \frac{g t^{2}}{L^{3}} B d\right]^{-0.8882}
$$


Proc. of the Seventh International Conference On Advances in Civil and Structural Engineering - CSE 2017. Copyright (C) Institute of Research Engineers and Doctors. All rights reserved.

ISBN: 978-1-63248-127-6 doi: 10.15224/ 978-1-63248-127-6-37

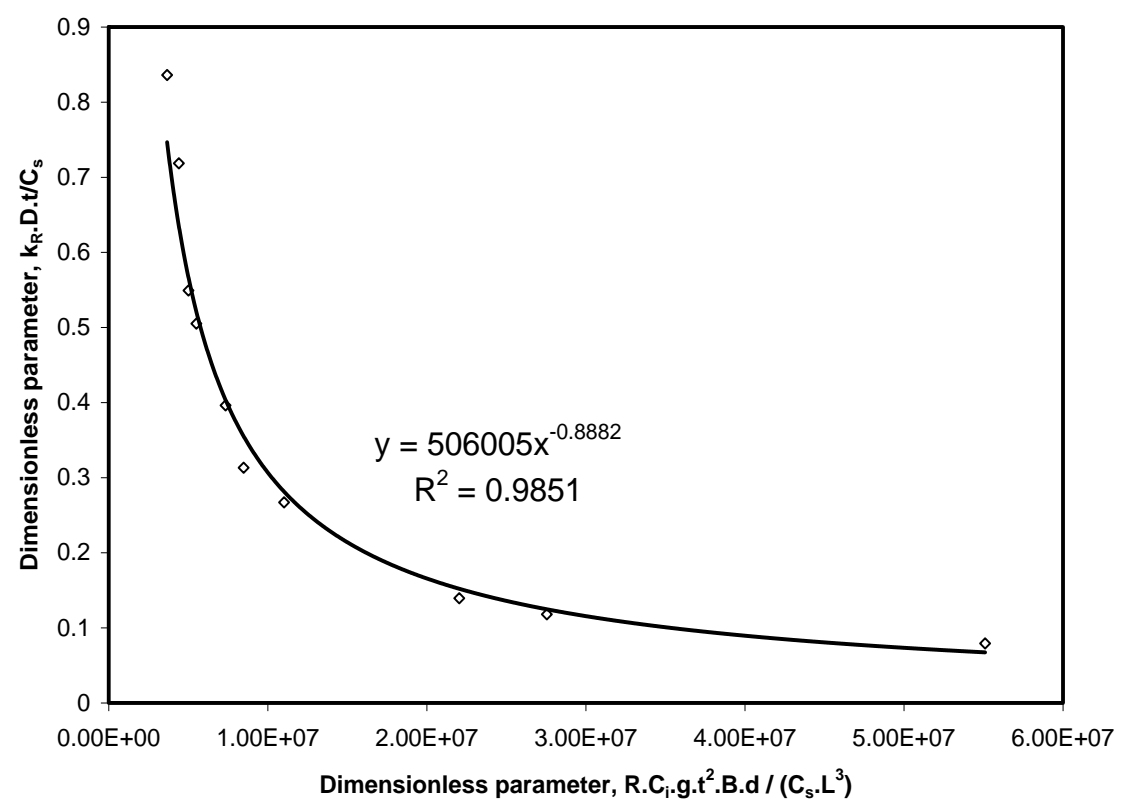

Fig. 1.Variation of dimensionless parameters $k_{R} \cdot$ D.t / $C_{s}$ with R.C. $\mathrm{i}_{\mathrm{i}} \cdot \mathrm{g} \cdot \mathrm{t}^{2} \cdot \mathrm{B} \cdot \mathrm{d} /\left(\mathrm{C}_{\mathrm{s}} \cdot \mathrm{L}^{3}\right)$.

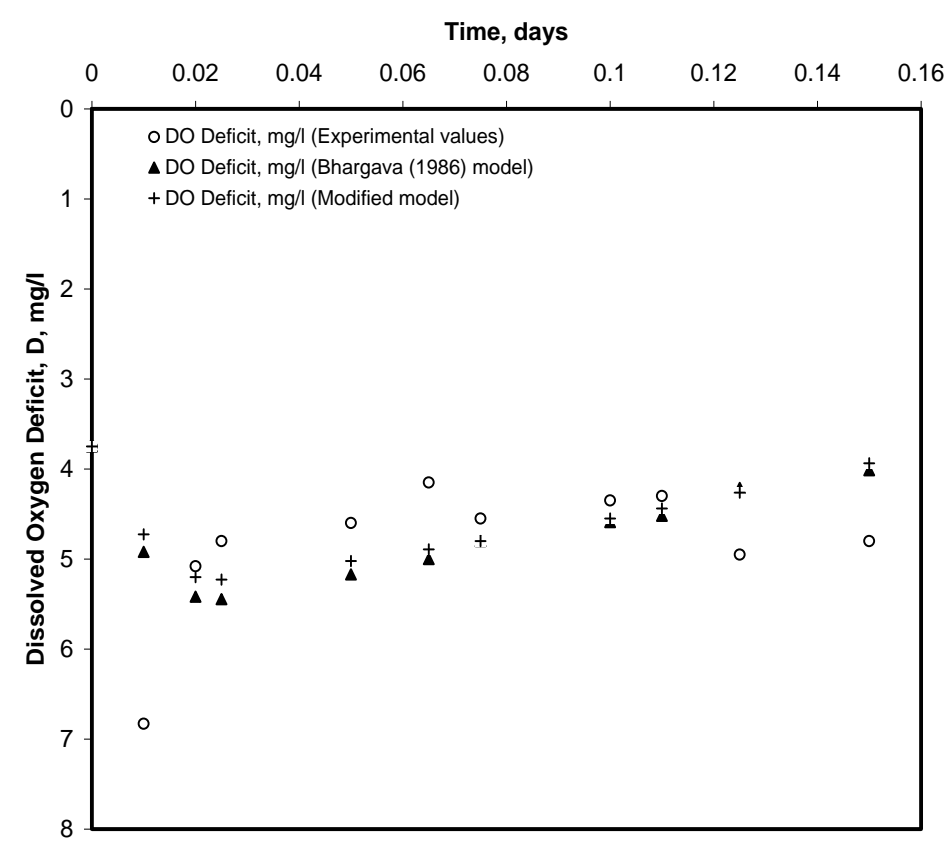

Fig. 2. Variation of dissolved oxygen deficit with time.

From Eq. (24), the value of $k_{R}$.D (equal to rate of re-aeration, $r_{R}$ ) was substituted after replacing L by V.t in Eq. (9) and the modified equation is expressed as:

$$
\left.\frac{d D}{d t}=m S_{0-x}\left(1-\frac{v}{d} t\right)+k S_{0-y} e^{-k t}-506005 . C_{s}^{1.8882} \cdot R \cdot C_{i} \cdot \frac{g}{V^{3}} B d\right]^{-0.8882} \cdot t^{-0.1118}
$$

The exact solution of Eq. (25), for $t<T$ (Transition time), $\mathrm{t}=\mathrm{T}=\mathrm{d} / \mathrm{v}$ and $\mathrm{t}>\mathrm{T}$ can be given respectively by Eqs. (26), (27) and (28) and expressed as: 


$$
\begin{aligned}
D= & m S_{0-x} t-m S_{0-x} \frac{v \cdot t^{2}}{2 d}-S_{0-y} e^{-k t}-569697 \cdot C_{s}^{1.8882} \cdot\left[R \cdot C_{i} \cdot \frac{g}{V^{3}} B d\right]^{-0.8882} \cdot t^{0.8882}+D_{0}+S_{0-y} \\
D= & m S_{0-x} \cdot \frac{d}{v}-m S_{0-x} \frac{d}{2 v}-S_{0-y} e^{-k \frac{d}{v}}-569697 \cdot C_{s}^{1.8882} \cdot\left[R \cdot C_{i} \cdot \frac{g}{V^{3}} B d\right]^{-0.8882} \cdot\left(\frac{d}{v}\right)^{0.8882}+D_{0}+S_{0-y} \\
D= & -S_{0-y} e^{-k t}-569697 \cdot C_{s}^{1.8882} \cdot\left[R \cdot C_{i} \cdot \frac{g}{V^{3}} B d\right]^{-0.8882} \cdot t^{0.8882}+D_{T}+S_{0-y} e^{-k \frac{d}{v}}+ \\
& 569697 . C_{s}^{1.8882} \cdot\left[R \cdot C_{i} \cdot \frac{g}{V^{3}} B d\right]^{-0.8882} \cdot\left(\frac{d}{v}\right)^{0.8882}
\end{aligned}
$$

The critical time, $t_{c}$ for $t_{c} \leq T$ and $t_{c}>T$ can be respectively modified to following equations:

$$
\begin{aligned}
& m S_{0-x}\left(1-\frac{v}{d} t_{c}\right)+k S_{0-y} e^{-k t_{c}}=506005 \cdot C_{s}^{1.8882} \cdot\left[R \cdot C_{i} \cdot \frac{g}{V^{3}} B d\right]^{-0.8882} \cdot t_{c}^{-0.1118} \\
& k S_{0-y} e^{-k t_{c}}=506005 . C_{s}^{1.8882} \cdot\left[R \cdot C_{i} \cdot \frac{g}{V^{3}} B d\right]^{-0.8882} \cdot t_{c}^{-0.1118}
\end{aligned}
$$

The critical DO deficit, $D_{c}$ for $t_{c} \leq T$ and $t_{c}>T$ can be determined by first determining $t_{c}$ from Eqns. (29) and (30) respectively by trial and error and using $t=t_{c}$ and $D=D_{c}$ in Eqs. (26) and (28).

The input parameters and the data for prediction of DO deficits were taken from the study of Bhargava (1986) and are presented in the text above and Table 1 . The predicted DO deficits were computed using Eqs. (10), (11) and (12) respectively for $t<T$ (Transition time), $\mathrm{t}=\mathrm{T}=\frac{d}{v} \mathrm{~d} / \mathrm{v}$ and $\mathrm{t}$ $>$ T for Bhargava (1986) model and Eqs. (26), (27) and (28) for modified model. Predicted DO deficits for both the models are computed only against the known experimental values and are given in Table 1. The predicted DO deficits along with the observed DO deficits are also plotted in Figure 2. It can be seen that the predictions are comparable and somewhat better by use of the modified equation than those predicted using Bhargava (1986) model. Thus, the modification proposed in the re-aeration rate term has practical utility in modelling DO behavior in rivers like Ganges having fast purification capacity.

The present work demonstrates that a dimensionless approach can be used to replace the rate of re-aeration term in DO deficit modelling. Traditionally, re-aeration coefficient has been the subject of dimensionless analysis. Errors may creep in the representation of re-aeration coefficient and this coupled with $\mathrm{D}$ term to represent reaeration rate may adversely affect the DO deficit computations. Thus, instead of following this line of attack, it was preferred to look into the possibility of representing re-aeration rate term itself. Results from Figs. 1 and 2 clearly indicate that this approach can also work. Due to lack of data on other rivers, the approach has not been tested for other conditions and it is expected that the concept presented in this paper will simulate further interest and applications in DO modelling in streams.

\section{Conclusions}

The present study is basically aimed to develop a functional relationship for re-aeration rate term using dimensionless approach, which is tested and found applicable to the rivers having fast BOD assimilation capacity like river Ganges in India. The concept developed gives satisfactory results in prediction of DO deficits in river Ganges. However, the validity of the approach needs further investigation on other rivers in future studies

\section{Acknowledgment}

The authors acknowledge to the Ministry of Human Resources Development (MHRD), Government of India, New Delhi for providing help and assistance in completion of this work. The authors also acknowledge to Director, MNNIT Allahabad, Allahabad, Uttar Pradesh, India for providing the facilities required for the work.

\section{References}

[1] D. S. Bhargava "DO sag model for extremely fast river purification." J. Environ. Engrg, ASCE, vol. 112, no. 3, pp. 573-585. ,1986.

[2] D. S. Bhargava, "Most rapid BOD assimilation in Ganga and Yamuna rivers.” J. Environ. Engrg., ASCE, vol. 109, no. 1, pp. 174-188., 1983.

[3] K. K. S. Bhatia, and E. A. McBean, "Steady state modelling of dissolved oxygen in river Speed (Canada).” J. IAH, vol. 9, no. 4, pp. 11-24, 1986.

[4] G. M. Fair, "The dissolved oxygen sag - an analysis." J. Sewage Works, vol. 11, no. 3, pp. 445., 1939.

[5] M. W. Streeter, and E. E. Phelps, "A study of the pollution and natural purification of the Ohio rivers." U.S. Public Health Bulletin No. 146. 1925. 